\title{
Comparative Meta-Transcriptome Analysis ofArabidopsis thaliana Under Organic Stress and Its Validation
}

\author{
Rajaseetharama Sekar ${ }^{1}$, Hema Jagadeesan* \\ \{rss.bio@psgtech.ac.in ${ }^{1}$, hj.bio@psgtech.ac.in* \\ Department of Biotechnology, PSG College of Technology, Coimbatore, 641001, India ${ }^{1}$
}

\begin{abstract}
Globalization and industrialization had led to the production of large quantities of waste with complex contents; these are prone to cause serious impact on sustainable development. Plant-microbe integrated system was found to be effective in treating specific waste streams in constructed wetlands or in rhizo-remediation. The molecular basis for this effective treatment vis-à-vis the interaction between plant and microbe in any such bio-augmented phytoremediation system is not well understood. Towards this end, a meta-analysis of transcriptomes of the model plantArabidopsis thaliana (Col-0) was performed by analysing 36 microarray samples belonging to seven microarray studies under various organic stresses. To understand the metabolic impact of the stress over the plant and their influence on root exudation, the genes involved in metabolic pathways of the root exudates were analysed. Totally 1313 genes involved in 26 metabolic pathways that in-turn corresponds to 55 root exudates were identified. Comparison of the DEG list of all stress conditions and the genes involved in root exudates, resulted in the short listing of four candidate genes that were highly influential both, in terms of expression pattern, leading to microbial enrichment and statistical significance.Further, to validate this in-silico result, a real time experimental set-up of Arabidopsis thaliana(Col-0) under simulated dye and microbial stress was designed. After treatment, Real Time Quantitative PCR was done for the four candidate genes and the expression pattern of those genes in real time conditions was obtained to corroborate thein-silico result.
\end{abstract}

Keywords: Plant-microbe interaction; organic stress; root transcriptome; root exudates;Arabidopsis thaliana; rhizo-remediation; meta-analysis of root transcriptome..

\section{Introduction}

Anthropogenic activities as part of economic development have led to the release of huge amount of waste containing hazardous components into the environment and have deleterious impact (Gudelj et al., 2011). Various remediation strategiesare adopted to overcome the effects caused by these hazardous wastes. Bio-remediation especially, phytoremediation is one among them which has gained its global importance because of its cost-effectiveness and ecofriendly approach(Glick, 2010).Plants release root exudates into their rhizosphere which varies depending upon various biotic and abiotic factors(Cheng and Gershenson, 2007). These root exudates contribute to selective enrichment of microbial community(Yang and Crowley, 2000). The microbial concentration in the rhizosphere may reach up to $10^{10}-10^{12}$ cells per gram, as compared to often $<10^{8}$ cells per gramin bulk soil (Cheng and Gershenson, 2007; 
Lynch and Whipps, 1990).Microorganisms in the rhizosphere contribute to different functions including organic and inorganic pollutant degradation(Burken and Schnoor, 1996). Bioaugmentation is another strategy in which the remediation can be tailored to a specific and dominant pollutant in the surrounding environment(Nzila et al., 2016). Studies have shown that plants along with microorganisms(bio-augmented-phytoremediation) can improve the efficacy of pollutant remediation(Agarwal et al., 2020).Still the molecular mechanism in the bio-augmented phytoremediation system is not well understood. This work aims to bridge the gap between the effectiveness of the augmented phytoremediation system and its molecular schema. The correlation between different organic stresses and the pathways that are modified, especially the biosynthesis of various root exudates was analysed. Based on the most significantly modulated genes in this pathway four candidate genes were selected and were analysed for their expression levels under a simulated plant-microbe treatment system for azodyes. This study was selected as such a plant-microbe integrated system was found to be more effective in treating azo dyes (Jayapal et al., 2018).

\section{Materials and Methods}

\subsection{Chemicals, microbes, plants and reagents}

All chemicals used in this study were analytical grade from either HIMEDIA or SIGMA. Arabidopsis thaliana (Col-O) seeds were obtained from Department of Plant Biotechnology, Madurai Kamaraj University, Madurai, India. Real time Quantitative PCR reagents were procured fromThermo Scientific and Takara Biosciences. Cow dung slurry was suspended in sterile water and filtered with sterile muslin cloth to remove the suspended particles. The cow dung slurry filtrate was used as source of microbes. All the experiments and assays were done in triplicates.

\subsection{Data retrieval, DEG prediction and sorting}

Microarray data sets of Arabidopsis thaliana roots under various abiotic stresses were retrievedfrom Gene Expression Omnibus (GEO) platform of NCBI. The microarray platform selected was GPL198. Datasets consisted probes that represents approximately 25,000 genes. Studies under these platforms were queried using "Arabidopsis thaliana" AND "Root" as keywords. The datasets were normalized using "limma" package of GEO2R tool(Lu et al., 2021). Multiple-testing corrections using Benjamini\&Hochberg (FDR) method was done to obtain adjusted P-values for the datasets. Differential Expressed Gene was sorted out with a cut-off of logarithmic Fold Change (log FC) more than +2 and P-value less than 0.05 using Rprogramming.

\subsection{Exudate gene retrieval and candidate gene selection}

Root exudates are important for microbial enrichment in the rhizosphere. Arabidopsis thaliana root exudates are comprised of about 55 different bio-molecules, including different classes of carbohydrates, amino acids and phenolics(Chaparro et al., 2013). The pathways which are involved in these exudate productions were annotated from KEGG Pathway database. The genes involved in the pathways were retrieved using KEGGREST (R-package).

The seven datasets used in this study were microarray datasets pertaining to roots ofArabidopsis thaliana under organic stress. The abiotic stresses were, 4-chloro- 6 methyl- 2phenyl pyrimidine (CMP), 2- (4- carboxyphenyl) tetra methyl imidazoline-1 oxyl- 3- oxide (cPTIO), Fenclorim, Norflurazone,Phenantherene, Dicamba (3, 6 dichloro 2 methoxy benzoic acid) and Probenazole.The genes involved in the exudation pattern were sortedfrom the set of 
up-regulated gene for all seven datasets along with their Fold change value using spreadsheets. Based on the Standard deviation of the expression fold and Count of Occurrence of upregulation for each gene in each condition, all those genes were sorted and a heat map was generated using "ggplot" module. Top four genes were selected as candidate genes based on their statisticalsignificance among various organic stress conditions and were up-regulated in four out of seven organic stress conditions

\subsection{Arabidopsis thaliana (Col-0) plant cultivation}

The Arabidopsis thaliana seeds were surface sterilized using 1\% Bleach solution for 5 minutes and $75 \%$ ethanol for 3 minutes and then rinsed with sterile water. Sterilized seeds were sown on plant tissue culture (PTC) bottles containing 0.5X MS(Murashige and Skoog, 1962)supplemented with $2 \%(\mathrm{w} / \mathrm{v})$ of sucrose and $1 \%(\mathrm{w} / \mathrm{v})$ of solidifying agent(Kazachkova et al., 2013). The seeds were incubated two days at $4{ }^{\circ} \mathrm{C}$ for stratification. After stratification, the bottles were incubated in the growth room under controlled conditions (16-h light (120 mmol m $\mathrm{m}^{-2} \mathrm{~s}^{-1}$ ) / 8-h dark) for 22 days. The 22 days old plantlets were used for further studies.

2.5 Transfer of plants to hydroponics

Twenty-two days old plants were removed from MS medium and were then rinsed with distilled water and sterile distilled water to remove the remains of MS medium on the root surface. The plants were transferred to $0.1 \mathrm{X}$ Hoagland's nutrient solution. $1.5 \mathrm{ml}$ Eppendorf tube lids (holed at centre) were used as floaters to hold the plant in the surface of the liquid medium. The tissue culture bottles containing the plants were maintained in tissue culture growth chamber under conditions of $16 / 8 \mathrm{hrs}$ light/dark cycles, temperature at $25 \pm 2^{\circ} \mathrm{C}$ and humidity $60 \%$ till the plants get adapted. The plant was maintained in hydroponics for four days, to stabilize its growth. The Hoagland's nutrient solution was replaced periodically(Sasikaladevi, 2017).

\subsection{Design of Experiment (DOE)}

Each trial was carried out in triplicates, with each tissue culture bottle containing three plantlets. For the experimental simulations,methyl red of $40 \mathrm{mg} / \mathrm{L}$ in $0.1 X$ Hoagland's nutrient solution and $1 \%(\mathrm{v} / \mathrm{v})$ of cow dung slurry filtrate in the Hoagland solutionas source of microbes were used. The treatment set up was maintained in tissue culture chamber overnight under conditions of $16 / 8 \mathrm{hrs}$ light/dark cycles, temperature at $25 \pm 2^{\circ} \mathrm{C}$ and humidity 60\%.(Table 1).

Table 1. Design of the study (P: Plant alone system: PM: Plant with microbe system; PP: Plant with pollutant system; PPM: hybrid system containing plant, pollutant and microbe)

\begin{tabular}{|l|c|c|c|c|}
\hline DOE & P & PM & PP & PPM \\
\hline Plant & + & + & + & + \\
\hline Microbes & - & + & - & + \\
\hline Methyl red & - & - & + & + \\
\hline
\end{tabular}

\subsection{Total RNA Extraction and total RNA quantification}

RNA was isolated from the roots of the treated plants as per the standard protocol(Ahn, 2009). Briefly, the root tissue of each experimental study was ground separately in mortar and pestle using Liquid Nitrogen and total RNA isolated using Trizol reagent. Isolated RNA was washed with $75 \%$ ethanol and air dried. RNA was re-suspended in TE buffer and stored at -80 ${ }^{\circ}$ Ctillfurther use. RNA was quantified using The SpectraMax ${ }^{\circledR}$ QuickDrop ${ }^{\mathrm{TM}}$ Micro-Volume Spectrophotometer. 


\subsection{Reverse Transcription}

Revert Aid First Strand cDNA synthesis kit was used for Reverse transcription as per the manufacturer's instruction. All reactions were initiatedwith 100ng of total RNA.

2.9 Real Time Quantitative PCR and Data analysis

All experiments were performed in Bio-Rad CFX96 system using TB® Green premix Ex TaqII. Each $10 \mu \mathrm{L}$ of reaction mixture contained, cDNA corresponding to 100ng of total RNA. Tublinbeta chainwas used as internal control gene(Hong et al., 2010). Primers forall four candidategenes and internal control genes were designed using Primer Pick of NCBI. The primers were designed targeting the reference sequence of individual genes. To eliminate nonspecific amplification, the primers were designed over exon-exon junction, with an amplicon size cut-off of 150bps. Also primers were obtained from previous works(Gunning et al., 2014). PCR thermo cycles program was programmed as $95.0^{\circ} \mathrm{C}: 30$ secs for Pre-denaturation, 40 cycles of Denaturation at $95.0^{\circ} \mathrm{C}$ for 5 seconds followed by amplification at $60.0^{\circ} \mathrm{C}$ for 30 seconds.

The stability of reference gene expression under different conditions was evaluated by comparing $C_{\mathrm{q}}$ values between treatment and control studies performed with an identical amount of purified cDNA. The expression fold change was determined by $\Delta \Delta C_{q}$ method(Livak and Schmittgen, 2001).

\section{Results and Discussion}

Plant - microbe interaction is one of the inevitable mechanisms that take place in a phytoremediation process. Complete understanding of the molecular background and biochemical signalling between plant and microbe in remediating the given pollutant stress is important to annotate the complete picture of a plant-microbe integrated phytoremediation system. Results of the meta-analysis done on Arabidopsis thaliana root transcriptome under various stress and real time validation of the candidate gene expression are discussed below.

\subsection{Data collection and curation}

Open access datasets of microarray experiments pertaining to roots of Arabidopsis thaliana subjected to various abiotic stresses, performed in ATH1-121501 AffymetrixArabidopsis thaliana Genome Array were retrieved (Table 2).

Table.2. Summary of Datasets retrieved from GEO database

\begin{tabular}{|l|l|l|}
\hline S. No & Type of stress & No. of datasets \\
\hline $\mathbf{1}$ & $\begin{array}{c}\text { Organics } \\
\text { Aromatic ring / amine }\end{array}$ & 7 \\
\hline $\mathbf{2}$ & Organics - others & 11 \\
\hline
\end{tabular}

The collected datasets were screened on studies that involved organic stress (especially compounds consisting aromatic rings and amine groups), as the aim is understandthe molecular background of plant-microbe integrated remediation, especially under azo dye stress. Theshort-listed studies included those with 4-chloro- 6 methyl- 2- phenyl pyrimidine (CMP), 2-(4- carboxyphenyl) tetra methyl imidazoline-1 oxyl- 3- oxide (cPTIO), Fenclorim, Norflurazone,Phenantherene,Dicamba (3, 6 dichloro 2 methoxy benzoic acid) and Probenazole as abiotic stresses and data relevant to roots of Arabidopsis thaliana were taken for further analysis. 
CMPis an herbicide safenerused to increase tolerance to the chloroacetanilide group of herbicides (Steel et al., 2011). CMP probably induces Glutathione S transferase genes in both root and suspension culture of Arabidopsis thaliana(Edwards et al., 2005). cPTIO belongs to nitronylnitroxides (NNO) compounds. These NNO compounds being stable organic radicals, react with nitric oxides (D'Alessandro et al., 2013). Hence, these cPTIOs are also termed as nitric oxide scavenger. Norflurazone is a fluorinated pyridazinone herbicide and is a Delta -6 desaturase inhibitor (Sopeña et al., 2011). Dicamba is a commonly used house-hold herbicide (Behrens et al., 2007). It is chlorinated derivative of o-anisic acid. Probenazole is widely used anti-fungal agent in rice cultivation. It protects the rice plant against Magnaporthegrisea, a rice blast fungus (Yoshioka et al., 2001). Phenantherene is a poly aromatic hydrocarbon (PAH) (Weisman et al., 2010), and are known to induce oxidative stress and leaf deformation (Alkio et al., 2005; Liu et al., 2009). All the above-described compounds have aromatic rings or amine groups, which is also similar while considering the stereo-chemical structure of azo dyes. Thus, these microarray studies were analysed for differential gene expression using GEO2R. The up regulated genes from each study were sorted out with a cut-off onlogFC greater than two and P- value lower than 0.05, using R programming. Among the 27,416 annotated protein coding genes of Arabidopsis thaliana (TAIR10, Gene annotation data), 2298 were up regulated cumulatively in the above stated stress conditions.

\subsection{Exudate gene retrieval and candidate gene selection}

Root exudates of Arabidopsis thaliana comprises of various organic compounds like carbohydrates, proteins, amino acids, phenolics, organic acids etc. Previous study on Arabidopsis thaliana (Col- 0) wild type grown in Murashige and Skoog medium (MS) supplemented with $3 \%$ sucrose and $0.9 \%$ Bactoagar at $25^{\circ} \mathrm{C}$ with a photo period of $16 \mathrm{hr}$ light/ $8 \mathrm{hrs}$ dark had shown to release around fifty five compounds in its root exudates, including various classes of sugars, amino acids, phenolics and organic acids (Chaparro et al., 2013). Each of the compound reported were taken for pathway analysis in KEGG pathway database. Totally 26 pathways were involved in the listed root exudate biosynthesis. Major pathways were amino acid and nucleotide synthesis pathway, fatty acid biosynthesis pathway, fructose and mannose biosynthesis pathway, Pentose phosphate pathway, pentose and glucoronate inter-conversion pathway. The relevant pathways annotated with the rate limiting enzymes were retrieved from KEGG database (Supplementary material).

Of the 26 annotated exudation pathways, five pathwaysnoted in Supplementary materialare involved in the exudation of predominant exudates. The genes involved in the pathways were retrieved using KEGGREST module of R (Tenenbaum, 2016). After compiling all the genes for individual pathways around 1312 protein coding genes were identified to be involved in the regulatory and anabolic pathway of the reported 55 root exudate compounds.

The selection of candidate gene was performed using Microsoft spreadsheets. The list of up-regulated gene sets for individual study were compared against the list of 1312 genes involved in exudation pattern and a heat map was generated using "ggplot" module of R. The heat map was generated based on the Standard deviation of the expression fold and Count of Occurrence of up-regulation for each gene in the various organic stress conditions (Fig. 1). 

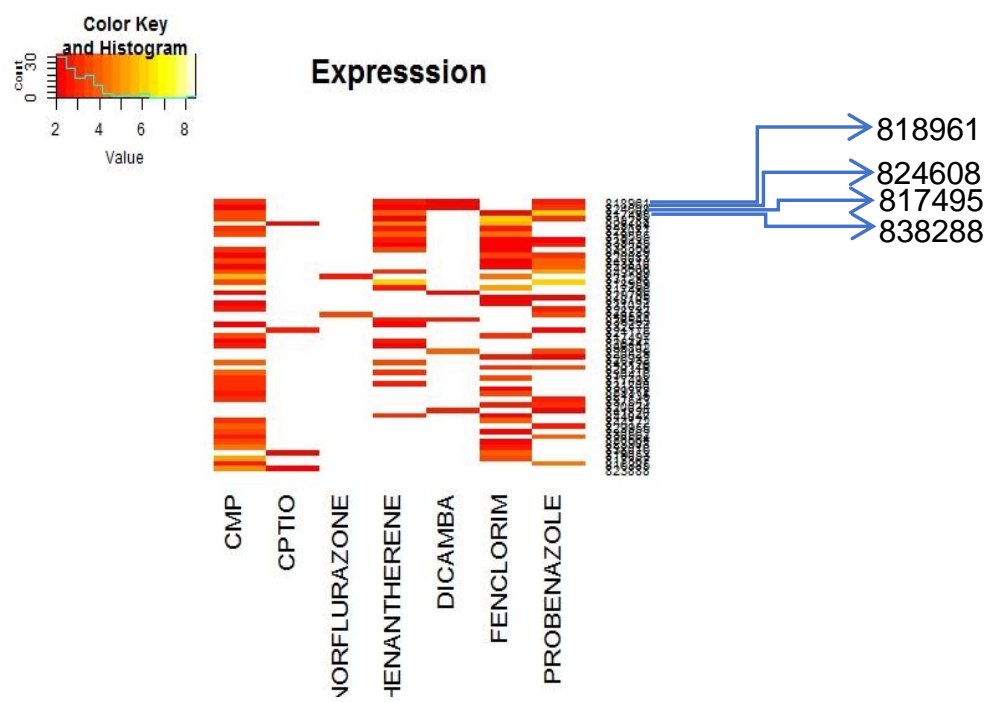

Fig.1. Heat map showing the top four candidate genes, based on Standard deviation of the expression fold and Count of Occurrence of up-regulation for each gene in the various organic stress conditions.

The top four candidate genes that have both higher expression and statistical significance were: 1. Glutathione S-transferase (GST) tau 4 (817495), 2. Glutathione S-transferase (GST) tau 24 (838288), 3. Chitinase family protein (818961), 3. Homolog of carrot EP3-3 chitinase (824608). The anabolic impact of those candidate genes in exudate metabolites are given in the Table 3

Table. 3.Significance of the candidate genes in exudate metabolism

\begin{tabular}{|c|c|c|c|}
\hline $\begin{array}{l}\text { S. } \\
\text { No }\end{array}$ & $\begin{array}{l}\text { Gene } \\
\text { ID }\end{array}$ & Gene name & Pathways involved \\
\hline 1 & 817495 & $\begin{array}{ll}\text { Glutathione } & \text { S- } \\
\text { transferase } \\
\text { (GST)tau } 4\end{array}$ & Oxoproline \\
\hline 2 & 838288 & 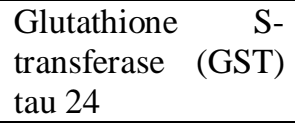 & Oxoproline \\
\hline 3 & 818961 & $\begin{array}{l}\text { Chitinase family } \\
\text { protein }\end{array}$ & $\begin{array}{l}\text { Fucose, } \\
\begin{array}{l}\text { Phosphate, } \\
\text { Mannosamine }\end{array}\end{array}$ \\
\hline 4 & 824608 & $\begin{array}{l}\text { Homolog of carrot } \\
\text { EP3-3 chitinase }\end{array}$ & $\begin{array}{l}\text { Fucose, Rhamnose, } \\
\text { Phosphate, Glucosamine }\end{array}$ \\
\hline
\end{tabular}

Glutathione S transferases (GSTs) are soluble proteins found in plants and animals. The GSTs have a molecular mass around 50kDA. These GSTs catalyses the conversion of the tripeptide glutathione to a polar S - glutathionylated product(Steel et al., 2011). They have a predominant role in metabolism as well as detoxification of drugs in animals (Wilce and Parker, 1994). Glutathione S transferases in plants were first identified on 1970's, in which it had a role in protecting maize crop from herbicide stress (Cobb and Kirkwood, 2000). Many GSTs have been identified and characterized both in plants and humans (Steel et al., 2011). 
In this work, two classes of GSTs showed their metabolic significance in biosynthesis of Oxoproline. Oxoproline is a precursor of Glutamic acid. Oxoproline is a well-studied intermediate in eukaryotic gamma- glutamyl cycle. These oxoproline is metabolized to glutamate by an ATP- dependent oxoprolinase(Griffith et al., 1978) in eukaryotes. But most of the prokaryotes lack this oxoprolinase(Niehaus et al., 2017).. Studies have enumerated the importance of putative 5- oxoprolinase genes in bio-remediating microbes for tolerating the lower water potential stress (Coronado et al., 2014). Thus it can be hypothesized that this leads to an enrichment of oxoprolinase positive microbes in the rhizosphere of Arabidopsis thaliana under these type of organic stress like herbicides, poly aromatic hydrocarbons

Chitinase group of enzymes belong to glycosyl hydrolysis family that degrade chitin to 14 linked N- acetyl D- glucosamine (Passarinho and de Vries, 2002). These are aalso termed as pathogenesis-related proteins(PRPs); they are induced by various fungal, bacterial and viral infections (Graham and Sticklen, 1993). Plants do not contain chitin, but still, most of the agricultural pests contain chitin in their cellular component. Plant secretes these chitinase to degrade fungal cell wall which acts as a defence mechanism (Passarinho and de Vries, 2002).

\subsection{Validation of expression pattern using $R T-q P C R$}

The candidate genes were analyzed for expression variation under four different conditions, Plant alone (P), Plant with microbial consortium (PM), Plant with pollutant (PP) and Plant with pollutant and microbial consortium (PPM) using RT-qPCR.

Equal amount of RNA sample from each test condition was taken for Reverse transcription and the synthesized cDNA was amplified in Real Time PCR.The RelativeFluorescence Unit (RFU) for fourcandidate genes under four different conditions with two primer sets each along with the two internal control genes were recorded and amplification graph was generated by the system. Non-template control (NTC) for all primer sets were included in the analysis. The amplification curve for each candidate gene in all four experimental conditions and the amplification curve for internal control gene (TUB2) are shown in Fig. 2. (a-e).

The amplification curves for all the four candidate genes clearly show the variability prevailing in different stress conditions. The amplification curves for internal control gene shows no variation among different stress condition, which indicates that the selection of internal control gene was satisfactory to perform relative quantification of expression variation in all candidate genes. The $\mathrm{Cq}$ value for each sample was obtained and further expression data analysis were performed using Delta-Delta $\mathrm{Cq}$ method and the results are tabulated in Table. 4. 
(a)

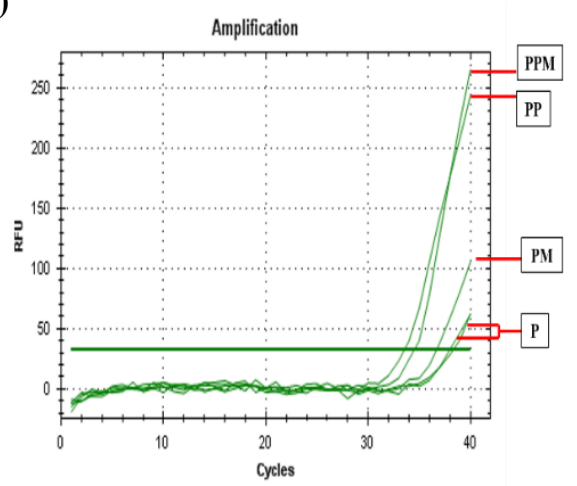

(c)
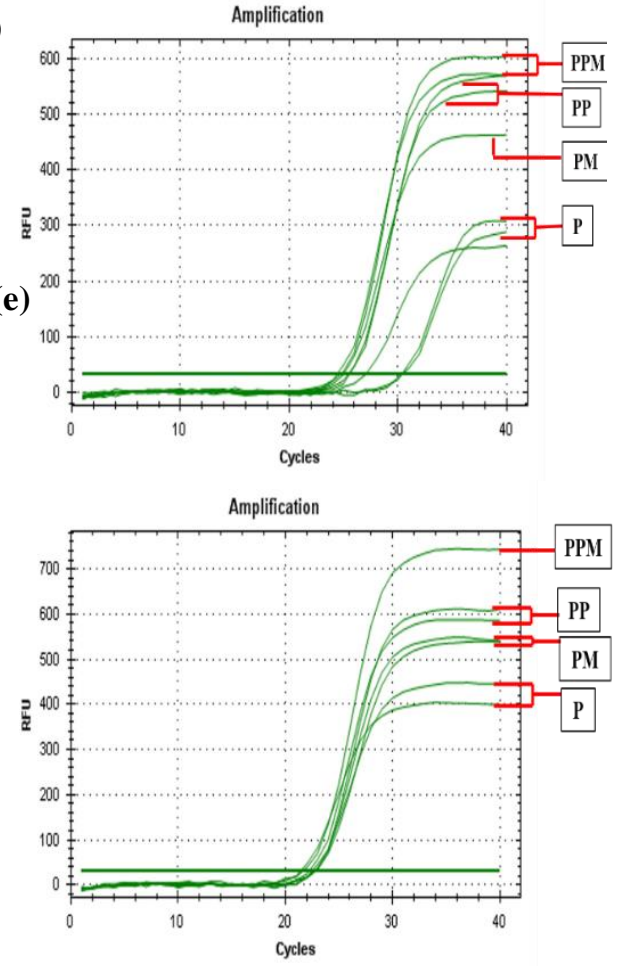

(b)

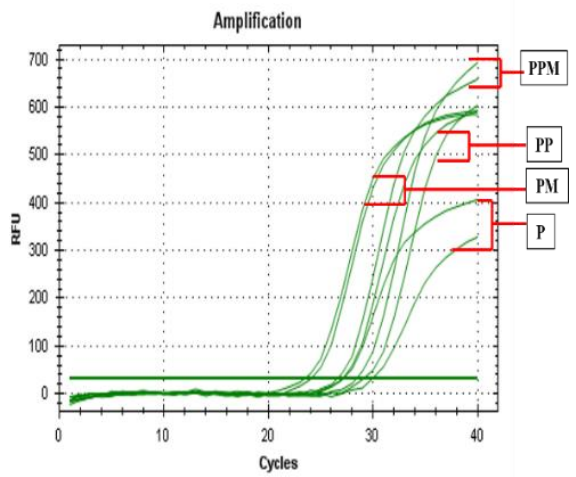

(d)

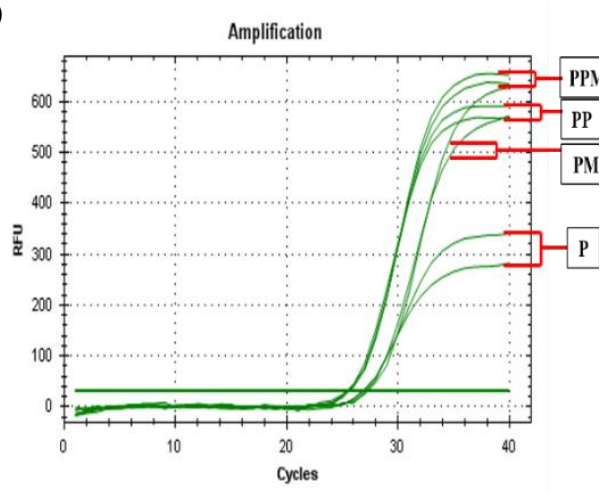

Fig.2. Amplification curve obtained by RT - q PCRunder four different experimental conditions

(a) Homolog of carrot EP3-3 chitinasegene, (b) Chitinase family protein gene, (c) Glutathione S-transferase (GST) tau 24 gene, (d)Glutathione S-transferase (GST)tau 4 gene, (e) internal control (TUB2) gene

Table. 4. Expression fold change of candidate genes in plant-microbe, plant-pollutant and plant with pollutant and microbe conditions 


\begin{tabular}{|l|l|l|l|l|}
\hline Condition & $\begin{array}{l}\text { Homolog of } \\
\text { carrot EP3-3 } \\
\text { chitinase }\end{array}$ & $\begin{array}{l}\text { Chitinase } \\
\text { family } \\
\text { protein }\end{array}$ & GST Tau 24 & GST Tau 4 \\
\hline PM & 1.97 & 12.7 & 3.86 & 1.64 \\
\hline PP & 5.43 & 7.26 & 2.206 & 0.942 \\
\hline PPM & 0.243 & 0.42 & 1.75 & 1.01 \\
\hline
\end{tabular}

The increase in expression pattern of the chitinase group of genes may be a defense mechanism adapted by the plant to tolerate the pathogenic stress which may include fungal species(Punja and Zhang, 1993). Also, up regulation was observed in GST family proteins. GSTs protect plant cells through detoxification, amelioration of oxidative stress and hormonal signaling in response to various biotic and abiotic stresses (Gullner et al., 2018; Mauch and Dudler, 1993). In plant with pollutant condition, the up-regulation of both chitinase and GST family proteins may be to enhance the level of oxoproline, Fucose, Rhamnose, Glu-1Phosphate, Glucosamine, Mannosamine in the root exudates This exudate compounds are amino acid precursors or derivatives of carbohydrates, which are well studied organic compounds in enhancing microbial enrichment(Chaparro et al., 2013). The expression of the candidate genes in plant with pollutant and microbial consortia condition was down regulated compared to the control (plant alone system). The chitinase group of proteins are a defensive response of the plant (Graham and Sticklen, 1993; Passarinho and de Vries, 2002; Punja and Zhang, 1993). In this scenario due to additional pollutant stress, the plant needs the associative function of microbes that has efficient remediation capabilities and therefore, a down regulation in chitinase family genes was observed. In addition, there was no significant, differential expression of GSTs in this treatment. Since microbe-associated remediation of the pollutant was in progress, the requirement for ROS scavenging GSTs family proteins might be reduced and hence no differential expression was observed in this system.

\section{Conclusion}

Bioremediation is a suitable technique to restore contaminated sites. Rhizoremediation with bio-augmentation could alleviate the limitations of phytoremediation. Understanding of the molecular mechanism behind the plant-microbe integrated pollutant remediating systems is still unclear. This study, on understanding the molecular mystery of plant-microbe integrated remediating system has revealed interesting insights on suppression of defence mechanism of plant to enhance microbial enrichment thereby tolerating the pollutant stress. Further detailed studies on the complete microbiome and transcriptome of both plant and microbes may help to the better understanding of this bio-augmented remediation strategy and thereby we can engineer this remediation system for enhanced efficiency, eco-friendliness and economic advantages. 


\section{Acknowledgements}

SekarRajaseetharama and Jagadeesan Hema acknowledge the support rendered by the Department of Biotechnology, PSG College of Technology for providing financial support to the work and also acknowledge Dr. P. Gopal, Department of Plant Biotechnology, Madurai Kamaraj University, Madurai for providing the seeds of A. thalianaand PSG College of Pharmacy, Coimbatore for providing the nucleic acid quantification facility at their campus.

\section{References}

[1]. Agarwal, P., Giri, B.S., Rani, R., 2020. Unravelling the Role of Rhizospheric Plant-Microbe Synergy in Phytoremediation: A Genomic Perspective. Curr. Genomics 21, 334-342. https://doi.org/10.2174/1389202921999200623133240

[2]. Ahn, J.H., 2009. RNA extraction from arabidopsis for northern blots and reversetranscriptase-PCR. Cold Spring Harb. Protoc. 4. https://doi.org/10.1101/pdb.prot5295

[3]. Alkio, M., Tabuchi, T.M., Wang, X., Colón-Carmona, A., 2005. Stress responses to polycyclic aromatic hydrocarbons in Arabidopsis include growth inhibition and hypersensitive response-like symptoms. J. Exp. Bot. 56, 2983-2994. https://doi.org/10.1093/jxb/eri295

[4]. Behrens, M.R., Mutlu, N., Chakraborty, S., Dumitru, R., Wen, Z.J., LaVallee, B.J., Herman, P.L., Clemente, T.E., Weeks, D.P., 2007. Dicamba resistance: Enlarging and preserving biotechnologybased weed management strategies. Science (80-. ). 316, 1185-1188. https://doi.org/10.1126/science.1141596

[5]. Burken, J.G., Schnoor, J.L., 1996. Phytoremediation: Plant uptake of atrazine and role of root exudates. J. Environ. Eng. 122, 958-963. https://doi.org/10.1061/(asce)07339372(1996)122:11(958)

[6]. Chaparro, J.M., Badri, D. V., Bakker, M.G., Sugiyama, A., Manter, D.K., Vivanco, J.M., 2013. Root exudation of phytochemicals in Arabidopsis follows specific patterns that are developmentally programmed and correlate with soil microbial functions. PLoS One 8, 1-10. https://doi.org/10.1371/journal.pone.0055731

[7]. Cheng, W., Gershenson, A., 2007. Carbon Fluxes in the Rhizosphere. Rhizosph. 31-56. https://doi.org/10.1016/B978-012088775-0/50004-5

[8]. Cobb, A., Kirkwood, R.C. (Ralph C.., 2000. Herbicides and their mechanisms of action.

[9]. Coronado, E., Roggo, C., van der Meer, J.R., 2014. Identification of genes potentially involved in solute stress response in Sphingomonas wittichii RW1 by transposon mutant recovery. Front. Microbiol. 5, 1-14. https://doi.org/10.3389/fmicb.2014.00585

[10].D’Alessandro, S., Posocco, B., Costa, A., Zahariou, G., Schiavo, F. Lo, Carbonera, D., Zottini, M., 2013. Limits in the use of cPTIO as nitric oxide scavenger and EPR probe in plant cells and seedlings. Front. Plant Sci. 4, 1-7. https://doi.org/10.3389/fpls.2013.00340

[11].Edwards, R., Del Buono, D., Fordham, M., Skipsey, M., Brazier, M., Dixon, D.P., Cummins, I., 2005. Differential induction of glutathione transferases and glucosyltransferases in wheat, maize and Arabidopsis thaliana by herbicide safeners. Zeitschrift fur Naturforsch. - Sect. C J. Biosci. 60, 307-316.

[12]. Glick, B.R., 2010. Using soil bacteria to facilitate phytoremediation. Biotechnol. Adv. 28, 367-374. https://doi.org/10.1016/j.biotechadv.2010.02.001

[13]. Graham, L.S., Sticklen, M.B., 1993. Plant chitinases. Plant J. 3, 31-40. https://doi.org/10.1046/j.1365-313X.1993.t01-1-00999.x

[14].Griffith, O.W., Bridges, R.J., Meister, A., 1978. Evidence that the gamma-glutamyl cycle functions in vivo using intracellular glutathione: Effects of amino acids and selective inhibition of enzymes. Proc. Natl. Acad. Sci. 75, 5405-5408. https://doi.org/10.1073/pnas.75.11.5405 
[15].Gudelj, I., Hrenović, J., Dragičević, T., Delaš, F., Šoljan, V., Gudelj, H., 2011. Azo dyes, their environmental effects, and defining a strategy for their biodegradation and detoxification. Arch. Ind. Hyg. Toxicol. 62, 91-101. https://doi.org/10.2478/10004-1254-62-2011-2063

[16].Gullner, G., Komives, T., Király, L., Schröder, P., 2018. Glutathione S-Transferase Enzymes in Plant-Pathogen Interactions. Front. Plant Sci. 9, 1-19. https://doi.org/10.3389/fpls.2018.01836

[17].Gunning, V., Tzafestas, K., Sparrow, H., Johnston, E.J., Brentnall, A.S., Potts, J.R., Rylott, E.L., Bruce, N.C., 2014. Arabidopsis Glutathione Transferases U24 and U25 exhibit a range of detoxification activities with the environmental pollutant and explosive, 2,4,6-trinitrotoluene. Plant Physiol. 165, 854-865. https://doi.org/10.1104/pp.114.237180

[18].Hong, S., Song, H.-R., Lutz, K., Kerstetter, R.A., Michael, T.P., McClung, C.R., 2010. Type II protein arginine methyltransferase 5 (PRMT5) is required for circadian period determination in Arabidopsis thaliana. Proc. Natl. Acad. Sci. 107, 21211-21216. https://doi.org/10.1073/pnas.1011987107

[19].Jayapal, M., Jagadeesan, H., Shanmugam, M., Danisha J, P., Murugesan, S., 2018. Sequential anaerobic-aerobic treatment using plant microbe integrated system for degradation of azo dyes and their aromatic amines by-products. J. Hazard. Mater. 354, 231-243. https://doi.org/10.1016/j.jhazmat.2018.04.050

[20].Kazachkova, Y., Batushansky, A., Cisneros, A., Tel-Zur, N., Fait, A., Barak, S., 2013. Growth platform-dependent and -independent phenotypic and metabolic responses of Arabidopsis and its halophytic relative, Eutrema salsugineum, to salt stress. Plant Physiol. 162, 1583-1598. https://doi.org/10.1104/pp.113.217844

[21].Liu, H., Weisman, D., Ye, Y. bei, Cui, B., Huang, Y. he, Colón-Carmona, A., Wang, Z. hua, 2009. An oxidative stress response to polycyclic aromatic hydrocarbon exposure is rapid and complex in Arabidopsis thaliana. Plant Sci. 176, 375-382. https://doi.org/10.1016/j.plantsci.2008.12.002

[22].Livak, K.J., Schmittgen, T.D., 2001. Analysis of relative gene expression data using real-time quantitative PCR and the 2- $\Delta \Delta \mathrm{CT}$ method. Methods 25, 402-408. https://doi.org/10.1006/meth.2001.1262

[23].Lu, L., Townsend, K.A., Daigle, B.J., 2021. GEOlimma: differential expression analysis and feature selection using pre-existing microarray data. BMC Bioinformatics 22, 1-20. https://doi.org/10.1186/s12859-020-03932-5

[24].Lynch, J.M., Whipps, J.M., 1990. Substrate flow in the rhizosphere. Plant Soil 129, 1-10. https://doi.org/10.1007/BF00011685

[25].Mauch, F., Dudler, R., 1993. Differential Induction of Distinct Glutathione-S-Transferases of Wheat by Xenobiotics and by Pathogen Attack. Plant Physiol. 102, 1193-1201. https://doi.org/10.1104/pp.102.4.1193

[26].Murashige, T., Skoog, F., 1962. A revised medium for rapid growth and bio assays with tobacco tissue cultures. Physiol. Plant. 15, 473-497.

[27].Niehaus, T.D., Elbadawi-Sidhu, M., De Crécy-Lagard, V., Fiehn, O., Hanson, A.D., 2017. Discovery of a widespread prokaryotic 5-oxoprolinase that was hiding in plain sight. J. Biol. Chem. 292, 16360-16367. https://doi.org/10.1074/jbc.M117.805028

[28].Nzila, A., Razzak, S.A., Zhu, J., 2016. Bioaugmentation: An emerging strategy of industrial wastewater treatment for reuse and discharge. Int. J. Environ. Res. Public Health 13. https://doi.org/10.3390/ijerph13090846

[29].Passarinho, P.A., de Vries, S.C., 2002. Arabidopsis chitinases: a genomic Survey. Arab. B. 1, e0023. https://doi.org/10.1199/tab.0023

[30].Punja, Z.K., Zhang, Y.-Y., 1993. Plant Chitinases and Their Roles in Resistance to Fungal Diseases 1. J. Nematol. 25, 526-540.

[31]. Sasikaladevi, R., 2017. Characterisation of root exudates during rhizoremediation of azo dye. PSG College of Technology, Anna University.

[32].Sopeña, F., Villaverde, J., Maqueda, C., Morillo, E., 2011. Photostabilization of the herbicide norflurazon microencapsulated with ethylcellulose in the soil-water system. J. Hazard. Mater. 195, 298-305. https://doi.org/10.1016/j.jhazmat.2011.08.039 
[33].Steel, P.G., Dixon, D.P., Edwards, R., Knight, K.M., Skipsey, M., Brazier-Hicks, M., 2011 Xenobiotic responsiveness of Arabidopsis thaliana to a chemical series derived from a herbicide safener. J. Biol. Chem. 286, 32268-32276. https://doi.org/10.1074/jbc.m111.252726

[34]. Tenenbaum, D., 2016. KEGGREST: Client-side REST access to KEGG.

[35].Weisman, D., Alkio, M., Colón-Carmona, A., 2010. Transcriptional responses to polycyclic aromatic hydrocarbon-induced stress in. BMC Plant Biol. 10.

[36].Wilce, M.C.J., Parker, M.W., 1994. Structure and function of glutathione S-transferases. Biochim. Biophys. Acta (BBA)/Protein Struct. Mol. 1205, 1-18. https://doi.org/10.1016/01674838(94)90086-8

[37]. Yang, C.H., Crowley, D.E., 2000. Rhizosphere microbial community structure in relation to root location and plant iron nutritional status. Appl. Environ. Microbiol. 66, 345-351. https://doi.org/10.1128/AEM.66.1.345-351.2000

[38]. Yoshioka, K., Nakashita, H., Klessig, D.F., Yamaguchi, I., 2001. Probenazole induces systemic acquired resistance in Arabidopsis with a novel type of action. Plant J. 25, 149-157. https://doi.org/10.1046/j.1365-313X.2001.00952.x 